\title{
STUDENTS' PERCEPTION ON E-PROCTORING SYSTEM FOR ONLINE ASSESSMENT
}

\author{
Annamaria De Santis, Claudia Bellini, Katia Sannicandro, Tommaso Minerva, \\ University of Modena and Reggio Emilia, Italy
}

\begin{abstract}
Online exams organization increased during the Covid-2019 pandemic. E-proctoring tools represented one of the systems used to take tests and monitor students' behaviour and integrity. Previous studies on the theme analysed the ease, technical issues and reliability of the system, students' academic results and digital skills in using online tools, effect of proctored testing on anxiety and performances.
\end{abstract}

The paper presents the results of the questionnaire administered to 541 students at University of Modena and Reggio Emilia to define how the use of e-proctoring systems for exams affects students' perceptions about their performances and teachers' role and impacts on concentration, attention, time management, anxiety, understanding, and motivation. The sample was predominantly divided into two equivalent groups in the answers: students who found positive elements in the experience, and students who saw the anxiety worsening using Smowl; students who were ready to use this tool with or without teachers also in the future, and students who found worrying the distance from the teacher. The exception to these results is students in Digital Education course degree who demonstrate greater confidence in proctored testing.

The inquiry underlines teachers' necessity to accurately design the exams and communicate with students in all teaching moments (include assessment).

Keywords: e-proctoring, e-assessment, Online Assessment, Exams, Teachers' and Learners' Roles, Students' Perceptions

\section{Introduction}

In the international context, the researches on online (formative or summative) assessment focused on various aspects: analysis of different online tools (ease, technical issues, and so on); types of tests used; validity and perceived reliability by institutions, teachers and 
learners (Walker \& Handley, 2016; Hillier et al., 2018; Costello et al., 2018, Janssen et al., 2019). Further studies compared paper with screen-based tests (Ranieri \& Nardi, 2018), and analysed students' academic results and digital skills in using online tools (Ilgaz \& Adanır, 2019).

Italian university rules (as in other countries and institutions) foresee the student's physical presence in the classroom for the carrying out of exams [see Decree n. 6 issued in 2019 by the Italian Ministry of Education, University and Research] and so, as a consequence, the organization and investigation on online exams and use of e-proctoring systems have limited till now.

Covid-19 lockdown pushed teaching and learning activities from traditional classrooms to digital environments. During the period of emergency, teachers and students developed their confidence with online learning tools and left out doubts and uncertainties in order to proceed with university training. In that situation, every training moment has changed: didactic with the teacher, self-learning, exams, in addition to the study environment itself. The whole academic community has continued and worked online (Minerva, 2020).

During the lockdown period and over, University of Modena and Reggio Emilia, who already had a long-time experience of blended courses based on Moodle LMS, adopted new and specific guidelines about assessment. Aware that, as a didactic moment, the assessment requires a particular reflection on methods, tools and environments, the attention was given principally to care and respect of students' status during the tests. Teachers focused on the identification of the candidate, the confidentiality of the student's data (GDPR 679/2016 and Italian Legislative Decree 196/2003), the public form of examination sessions, the quality and fairness of the test. Oral exams were held simply using one of the videoconference tools already available for streaming lessons. Thanks to the federated organisation of the university in departments, each one could organize the written exams depending on disciplines, tests, and costs of the digital tools chosen. Three were the possible solutions proposed by central governance:

- $\quad$ Live proctoring - small groups of students held exams in videoconference sessions with the presence of one or more teachers. The test can be a questionnaire on Moodle (platform called "Dolly", as a personalization form) or another type of assignment (e.g. production of software codes or paper exercises/texts);

- Live proctoring with SEB - as in the previous solution, students participated in exams while connected in a videoconference environment. In this case, the exams were questionnaires with open/close-ended answers made on Moodle and controlled through Safe Exam Browser. This well-known browser can manage access to the device functions and other pages or applications; 
- E-proctoring - students autonomously completed exams on Moodle while the e-proctoring system automatically revealed students' behaviour and integrity by checking desktop and webcam for the entire length of the test. Students registered to the system to verify their identity in the days before exams, checked their devices according to technical suggestions, downloaded the proctoring software, and completed their tests alone at home. Teachers prepared the exams well in advance, booked the proctoring system's use, sent students information and passwords to access exams on Moodle. In this solution, teachers were not engaged during the exam (their presence was not necessary) but at the end when they had to check the images and reports saved by the system from the webcam and desktop.

Carina S. González-González and colleagues (2020) define an e-proctoring system as "system formed by electronic tools that allows the monitoring of the remote evaluative process through telematic resources, trying to make the results reliable" (p.2). According to the authors, trust that is "the degree of security and privacy that users of a new technological tool expect to have when using it" (p.5) is the most decisive element in the implementation of such a tool for assessment in an institution. Studies about the virtual system, used to prevent plagiarism and cheating (Reisenwitz, 2020), regard the impact of proctored testing on anxiety, performances and learning styles (Wellman, 2005; Kolski \& Weible, 2018).

In order to examine the students' experience at University of Modena and Reggio Emilia, a questionnaire on the e-proctoring system was administered. The results are discussed in the next pages.

\section{Methods}

The aim of this research is to define how the use of e-proctoring systems for exams affects students' perceptions about their performances and teachers' role. Besides, the study points out what the opinions of students on the reliability of the tool are.

We administered a (not mandatory) questionnaire to students after completing their exams using the proctoring system called Smowl. The questionnaire is composed of 14 closeended questions and two open-ended for the comments. Three questions regard the age, previous degree, and working status. The following 11 items on a 4 levels scale (1 Completely disagree; 2 - More disagree than agree; 3 - More agree than disagree; 4 Completely agree) focus on perceived performance, teachers' relationship, reliability of the tool, impact of the proctoring system on concentration, attention, time management, anxiety, understanding, and motivation.

After collecting the first results, we added two questions to clarify the results obtained until that moment. These two questions were proposed to students that chose the lower options 
in the scale (1 or 2 ) to describe their performance using Smowl and the impact of the proctoring system on anxiety and concentration.

\section{Results}

732 students replied to the survey, and we considered 541 observations for the analysis removing N/A from the original dataset. Among these, 194 observations include the two additional questions.

The survey participants belonged to 31 courses of the degree in Medicine $(\mathrm{N}=302)$, Psychology $(\mathrm{N}=117)$, Digital Education $(\mathrm{N}=75)$, Informatics $(\mathrm{N}=35)$, Biotechnology $(\mathrm{N}=10)$, and Education $(\mathrm{N}=2)$. During the Coronavirus pandemic, all these courses were delivered online. In normal conditions, the courses in Psychology, Education, and Digital Education are blended degrees, the others as traditional (face-to-face lectures). Smowl was used for final tests in all courses, except for the degree in Digital Education (DE), where it was used for preliminary tests on numeracy skills also before Covid-19 lockdown.

The sample was mainly made of students between 20 and 24 years old (74.7\%). Only 10.7\% of respondents had a previous degree, $27.0 \%$ were currently working. The number of workers was lower among students enrolled in traditional courses (17.9\%), higher in the degree course in DE (62.7\%). This last value probably deals with the age of the students enrolled in DE degree: 45.3\% were between 20 and 24, 37.4\% between 35 and 55 .

Table 1 shows the answers to the questions related to students' perceptions of their performance during exams. $68.1 \%$ of the respondents declared that their performance was not better when using the e-proctoring system. We asked a lower percentage of students if their performance went worse or was the same compared to those of the face-to-face exams: $46.5 \%$ confirmed that their performance was worse, $53.5 \%$ that their performance was the same.

The sample was divided into two groups of equivalent dimensions on the items related to the positive/negative impact of the proctoring system on attention, understanding, and motivation (Table 2). The percentage of students who thought that the e-proctoring system's use negatively influenced their levels of anxiety and concentration during the exam is higher than $50 \%$ (57.0\% anxiety, $54.9 \%$ concentration). On the contrary, $57.1 \%$ of the respondents assumed that this system improved time management during the test. For this question, we also asked for clarification of a sub-sample that chose options 1 or 2 as a reply in the previous query. Two-thirds of the respondents had a negative effect on levels of concentration, attention, time management, anxiety, understanding, and motivation.

In the open-ended question, the students declared that this way of taking the examination causes anxiety because, during the test, it is necessary to be careful of the technical and 
practical issues: internet connection, control of movements (eyes and whole-body), lighting, management of the devices. They were worried that they would fail because of a technical malfunction and not because of their performance.

If we consider the sub-sample of the DE students, the above percentages change. $66.7 \%$ of students chose options 3 and 4 in the question related to their perceived performance level. A percentage of students between $65 \%$ and $80 \%$ believe that using e-proctoring tools positively affects their attention, anxiety, understanding (and so on) during examinations.

Table 1: "My exam performance with the e-proctoring system was better than the one I would obtain in the face-to-face assessment".

\begin{tabular}{lcc}
\hline \multicolumn{1}{c}{ Options } & Total (\%) & $\begin{array}{c}\text { Degree in } \\
\text { Digital Education (\%) }\end{array}$ \\
\hline 1 - Completely disagree & 24.8 & 12.0 \\
2 - More disagree than agree & 43.3 & 21.3 \\
3 - More agree than disagree & 26.2 & 52.0 \\
4- Completely agree & 5.7 & 14.7 \\
\hline
\end{tabular}

Table 2: "The e-proctoring system use in the test positively impacted concentration, attention, time management, anxiety, understanding, and motivation during the exam".

\begin{tabular}{lccccccccccccc}
\hline Options & $\begin{array}{c}\text { Concentration } \\
(\%)\end{array}$ & \multicolumn{2}{c}{$\begin{array}{c}\text { Attention } \\
(\%)\end{array}$} & \multicolumn{2}{c}{$\begin{array}{c}\text { Time } \\
\text { management } \\
\end{array}$} & \multicolumn{2}{c}{$\begin{array}{c}\text { (\%) } \\
\end{array}$} & TOT & DE & TOT & DE & TOT & \multicolumn{2}{c}{$\begin{array}{c}\text { Anxiety } \\
(\%)\end{array}$} & \multicolumn{2}{c}{$\begin{array}{c}\text { Understanding } \\
(\%)\end{array}$} & \multicolumn{2}{c}{$\begin{array}{c}\text { Motivation } \\
(\%)\end{array}$} \\
\hline 1 & 25.1 & 12.0 & 19.0 & 9.3 & 17.0 & 6.7 & 34.8 & 9.3 & 15.7 & 6.7 & 17.9 & 8.0 \\
2 & 29.8 & 17.3 & 30.3 & 17.3 & 25.9 & 13.3 & 22.2 & 20.0 & 31.8 & 17.3 & 32.0 & 26.7 \\
3 & 32.7 & 44.0 & 37.2 & 48.0 & 39.7 & 46.7 & 22.6 & 30.7 & 39.0 & 49.3 & 36.8 & 41.3 \\
4 & 12.4 & 26.7 & 13.5 & 25.3 & 17.4 & 33.3 & 20.5 & 40.0 & 13.5 & 26.7 & 13.3 & 24.0 \\
\hline
\end{tabular}

$62 \%$ of the students agreed to use Smowl for exams in other courses and said that online assessment using tools like this is as reliable as traditional face-to-face exams. Students appreciated using the e-proctoring tool to reduce the physical distance and the time to reach the university. The online assessment resulted in a useful reply to the studentsworkers' needs.

In questions related to the teachers' relationship, $55.0 \%$ of students affirmed that the teachers or tutors' absence during the online test is not critical. However, only $42.9 \%$ thought that online assessment didn't increase the distance between students and teachers. In the open-ended question, the students often indicated that speaking with the teachers during the test can help ask clarifying questions about the exam texts. The same students recognized that this presence is less necessary when the exam's rules, goals, and text are clear from the beginning.

The answers by Digital Education students for these last two topics differ from the total sample. $82.7 \%$ agreed to use Smowl for other exams, $76.0 \%$ believed the tool is reliable, 
$70.6 \%$ were not worried by the absence of the teachers during the exam, and $61.4 \%$ didn't see the proctoring system as a tool that increased the distance between teacher and students.

\section{Discussions and conclusions}

During the pandemic, in our universities teachers and students discovered distance learning and were "obliged" to experiment online solutions for teaching activities and also for exams. Their daily activities changed and a set of tools for recording, streaming lessons, online communication and assessment appeared in their lives.

E-proctoring with Smowl seemed a good choice not to stop training and manage exams of a large number of students in this emergency period. We experimented with this tool carrying out very different tests for score of difficulty, discipline, type, and year. In our university and our e-Learning centre, this operation required the establishment of a specific support and training team for teachers and students on Smowl and the quiz creation on Moodle.

We administered a questionnaire to students to collect their opinions and perceptions in the use of the e-proctoring tools and investigate the weaknesses, opportunities, and challenges of the online assessment.

The sample was predominantly divided into two equivalent groups in the answers: students who found positive elements in the experience, and students who saw the anxiety worsening using Smowl; students who were ready to use this tool with or without teachers also in the future, and students who found worrying the distance from the teacher. Some of them exposed the difficulties of applying this new technological approach and this new communication style with teachers. Others underlined the advantages in time management both during the exams and in reaching the university place.

After these results, we are interested to know what the students using live proctoring (see Introduction) could reply to these questions, considering that during exams in live proctoring students and teachers share the same videoconference environment just like in a classroom.

We questioned ourselves on how much the habit and digital skills in the use of a digital tool influence students' perception of their performance. The satisfaction percentages on the proctored system are higher in students' subsample in Digital Education (DE). Their opinions were very useful in comparing results between two different ways of using eproctoring. Mainly final exams in the courses involved in this research were taken through Smowl. In DE degree, students used Smowl for preliminary tests to pass before the beginning of the second course year. They have the possibility to repeat the test once a 
month during the first year and begin using Smowl before Covid-19 pandemic. A higher number of adults is enrolled in the degree course that, moreover, is delivered two-thirds online. DE graduates are instructional designers and experts in the use of digital technologies in education and training. Even though they are freshmen, these students may be more aware of digital educational tools, and we can assume that the greater confidence in the e-proctoring mode may also depend on this.

The inquiry underlines the necessity for teachers to accurately design the exams and the communication with students in all teaching moments (include assessment): the choice of types and moments of assessment has to be strictly linked to the learning outcomes and includes soft and professional skills (García-Peñalv et al., 2020).

Once the emergency phase is over, the effort in teaching during the Covid-19 pandemic will make sense if the whole institution will benefit from good practices on distance learning, studies on the online assessment, and creative solutions against daily challenges.

\section{References}

Costello, E., Holland, J., \& Kirwan, C. (2018). The future of online testing and assessment: question quality in MOOCs. International Journal of Educational Technology in Higher Education, 15(1), 42.

González-González, C. S., Infante-Moro, A., \& Infante-Moro, J. C. (2020). Implementation of E-proctoring in Online Teaching: A Study about Motivational Factors. Sustainability, 12(8). doi:10.3390/su12083488

García-Peñalvo, F. J., Abella-García, V., Corell, A., \& Grande, M. (2020). La evaluación online en la educación superior en tiempos de la COVID-19. Education in the Knowledge Society (EKS), 21, 26. doi:10.14201/eks.23013

Hillier, M., Grant, S., \& Coleman, M. (2018). Towards authentic e-Exams at scale: robust networked Moodle. Open Oceans: Learning Without Borders, 131.

Ilgaz, H., \& Adanır, G. A. (2020). Providing online exams for online learners: Does it really matter for them? Education and Information Technologies, 25(2), 1255-1269.

Janssen, J. P. W., Guerrero Roldan, A., Hermans, H. J. H., \& Noguera, I. (2019). TeSLA e-Assessment Model \& Framework. TeSLA. Retrieved from https://research.ou.nl/en/publications/tesla-e-assessment-model-ampframework

Kolski, T., \& Weible, J. (2018). Examining the relationship between student test anxiety and webcam based exam proctoring. Online Journal of Distance Learning Administration, 21(3). 
Minerva, T. (2020). Educational dinosaurs in the digital-pandemic era: the need for a digital framework and an emergency framework in education. Journal of e-Learning and Knowledge Management, 16(3), I-III. https://doi.org/10.20368/1971-8829/1135348

Ranieri, M., \& Nardi, A. (2018). Su carta o sullo schermo? Studio sulle percezioni delle verifiche digitali in ambito universitario. Italian Journal of Educational Technology, 26(3), 56-70.

Reisenwitz, T. H. (2020). Examining the Necessity of Proctoring Online Exams. Journal of Higher Education Theory and Practice, 20(1).

Walker, R., \& Handley, Z. (2016). Designing for learner engagement with computer-based testing. Research in Learning Technology, 24. Retrieved from https://journal.alt.ac.uk/index.php/rlt/article/view/1760/xml_45

Wellman, G. (2005). Comparing learning style to performance in on-line teaching: Impact of proctored v. unproctored testing. Journal of Interactive Online Learning, 4(1), 20-39. 